\title{
What is missing? Reflections on Indigenous Health - Interview with Axel Kroeger and Françoise Barbira-Freedman
}

\author{
Interviewer: ALINE REGITANO \\ Universidade de São Paulo, São Paulo, São Paulo, Brasil \\ alineregitano@usp.br
}

DOI 10.11606/issn.2316-9133.v29i2pe180514

Axel Kroeger is a professor on International Community Health at the Liverpool School of Tropical Medicine/University of Liverpool, and is currently engaged in undergraduate and postgraduate teaching at Freiburg University in Germany. He is supporting the World Health Organization in Geneva (TDR-WHO) with the Special Program for Research and Training in Tropical Diseases. Axel has several works regarding Health focused in low and middle-income countries in Latin America and Asia and has done extensive fieldwork in those places. He was for four years a medical doctor in the rainforest of Ecuador and has maintained links to this area until now.

Françoise Barbira-Freedman is an affiliated lecturer in the Department of Social Anthropology at the University of Cambridge. She has done long periods of fieldwork among Keshwa Lamas (formerly known as Lamistas) people throughout the years, and has had a lifetime dedication on analysing childbirth, with a series of inspiring publications reflecting on childbirth, shamanism and ethnobotany in Amazon. She is also the founder and director of the worldwide Birthlight movement.

We met for this interview at Google Meet, each one of us in a different time zone. Axel was in Geneva, Switzerland; Françoise was in Cambridge, England; and I was in Campinas, Brazil.

ALINE REGITANO: Françoise, Axel, you have a series of fascinating collaborative works on Indigenous Health. Under what conditions did your meeting take place? How has the fact that you have backgrounds in different areas contributed to verifying common issues? 
FRANÇOISE BARBIRA-FREEDMAN: Well, I was trying to remember how we met and I am not completely sure...I think I wrote an article in Amazonia Peruana, and you saw it, and we got in touch or something...

AXEL KROEGER: I think you were also preparing this conference on Amazon...

FRANÇOISE BARBIRA-FREEDMAN: Oh, that is right. At the time of the Amazon conference, on September of 1978.

AXEL KROEGER: We both noticed that we were working with mainly the same, or very similar indigenous groups. Françoise was in Peru, working with Lamistas. I was in Ecuador, working with Shuar/Achuar. They were the same ethnic group, but went into different branches, and therefore it was interesting to compare differences, but also, what was the same among them.

FRANÇOISE BARBIRA-FREEDMAN: We had similar ideas as well about cultural change, discontinuities and continuities. I thought Axel was quite an advanced thinker for a medic and was very happy to collaborate.

AXEL KROEGER: For me, it was a new thing to work with an anthropologist I could understand [laughing]. And not only theory, but also the practical part, experiences, case studies, comparative work, so it was really a very good time.

ALINE REGITANO: The book "La lucha por la salud indígena", published in 1992, the result of long-standing fieldwork, is work for our days still. There is "Salud y Enfermedad en el Alto Amazonas", translated into Portuguese in this issue of Cadernos de Campo. What has changed since then, in terms of health care? Are the problems the same?

AXEL KROEGER: The first, what is more or less similar to that time is the fight for land. I was there in the 1970s and the big discussion was how they get their land certified by the country's land titles, etc. Now I have heard in the area where I was working, that the Ecuadorian government has given to a Chinese company the possibility to build up a big camp for copper mines, etc., I think. Of course, the local population is fighting against it, without major chances, I would say, to win the battle, but it illustrates very well that there are always these uncertainties for the vulnerable groups. Brazil is an excellent example for this. You have governments who are very indigenous prone, helpful and who have the legislation on behalf of these population groups, but when there is another minister, or leader in the country, then, it all changes and the vulnerable will suffer. This is a concern, which occurred in those days, and it is more or less similar to what happens nowadays. 
In terms of health, the major issues are more or less the same, I think. They are related to human life, to humanity. For instance, what I was fascinated by was pusanga, this is a love magic that provokes a man to be attracted to a woman, and a woman to be attracted to a man, which we have found very much also in other Latin American countries, Mexico, Argentina. It also occurs in Asian countries; so, let me say, this is a response to some basic needs. The other one is jealousy (envidia). Jealousy is a big problem in small communities and this was a reality nowadays.

The changes that occurred are important, first regarding the pathogens. In those days, early 1970s, you got infectious diseases coming in and killing people, like whooping cough. We had several outbreaks of whooping cough. Then measles was a big problem, so we vaccinated quite intensively. Influenza, common cold, etc., were really a threat for the local population. Also, tuberculosis entered the remote jungle areas in those days and intestinal worms (particularly Ascaris) were an increasing problem parallel to western "civilization". Now it is HIV/AIDS. HIV/AIDS entered quite heavily into the Shuar-Achuar area, more in the Shuar part, because they are more exposed and connected with the colonists, the "colonos" or settlers from other parts of the country. It is an increasing problem particularly, of course, because there are no drugs, or, there is no program organized for them. Primary health care, including these central health issues, continue to be a major challenge and an issue in the area.

FRANÇOISE BARBIRA-FREEDMAN: On the Peruvian side it is very similar to what Axel described. I would say that there is much more population pressure on the environment and more inequality. We have large plantations of oil palm, and irrigated rice that has taken a lot of water from the rivers, so there are more contrasts between floods and droughts. This makes survival challenging, as indigenous people are pushed on less good lands and which they compete about with colonists that have migrated from the Andes. There is more population pressure, deteriorated environment and more focus on the regional hospital. The old system of sanitarios (primary health workers) has collapsed long ago, so now people take the road and go to the drugstore, or go to the hospital for care. In terms of pathologies, I agree with Axel, in the way that what we used to call the magical illnesses, like pusanga and susto, are still there. They are present and very nearly dominant, and that people use the same strategies to cure them as they did before. The same old problems of snakebites are there, the same dual strategies of going to the hospital as quickly as possible, but also going to the shaman to get treatment for the snakebite. I find a lot of continuity in a deteriorated environment and ecology, and less access to the traditional remedies, much more difficult to source the plants and the ingredients for traditional remedies.

ALINE REGITANO: Is it the case that the Shuar-Achuar people work on the plantations? 
AXEL KROEGER: It was already the case in the 70s, when I was there in a very remote area, an Achuar area, people were living in their close environment, and they still had their long hair, painted their faces and wore the feather crown. Once I observed that a youngster of 17 or 18 years old came back from the oil fields, in Ecuador, and he was really the novelty and everybody, the younger people wanted to talk to him. He brought a radio with him and this was very attractive, at least for the younger people. I am sure the same happens nowadays with other attractions and temptations. But on the other hand, indigenous people now living in urban environments are suffering, mainly women are suffering, because they have small houses or flats and have a very poor environment compared to what they had previously in the 70s. It happened that families went back into their original environment, because they could not stand the lifestyle they saw from the colonists. Of course, they usually had a very poor copy of the "new life style" and I suppose this happens in many places. I have seen rehousing programs in Venezuela, when the country was still rich, and they wanted to do something for the indigenous people, and they did it like "modern people" thinking that this is the best way to do it. They constructed houses one next to the other and brought the indigenous people there; but these people were suffering, they disappeared very quickly, then others were coming, but it really never worked. Because these kinds of settlements were not adapted to their own lifestyle. So there was a good will, there was a policy, but it was poorly designed and poorly executed.

ALINE REGITANO: Both of you have looked at Health through fieldwork conducted among non-Western groups in places like Peru, Ecuador, Nepal and Bangladesh. Based on your experiences, how can we deal with the differences, sometimes irreconcilable, of conceptions and practices that coexist in the same space (hospitals, indigenous health houses, for example)?

FRANÇOISE BARBIRA-FREEDMAN: I followed very closely the introduction of the parto vertical in both Peru and Ecuador, and it has been abandoned because it did not work. The idea was good. Encourage women to give birth in their traditional birth positions, but it was done in such a very rigid and medicalized way, that the women preferred to be on the bed, because they did not recognize that practice as parto vertical, although the intention was there. They always give birth standing, hanging from something, and they said, "okay, you come to hospital and you can do that". They installed a rope in the labour room, but they were all with gowns and masks, and the women did not feel at ease at all. So, it was a good initiative, as Axel said, about the houses in Venezuela, but there's something missing. Maybe we can speak about what this missing element is, because it's probably the most important one.

AXEL KROEGER: Yes, I have seen a similar situation in Chiapas, Mexico. Next to the hospital was founded a casa da partera and they made quite a lot of propaganda but women 
did not accept. They did not go there and this is also again this missing, what is missing that they don't feel at home when they are going there...

ALINE REGITANO: Is the case that women are now going more and more to give birth at the hospitals?

FRANÇOISE BARBIRA-FREEDMAN: Well, in Peruvian Amazonia it's illegal not to give birth in the hospital, so first of all, if a woman gives birth at home, she doesn't get the government grant that is given on the birth of a child, which is, I think about 180 dollars, and it's much more difficult for her to get a birth certificate. She has to go to the town, has to find money and then, if the midwife is caught attending her, she can be denounced. I visited two midwives in jail a few years ago. The midwives are criminalized, and hospital transfers are enforced to promote better maternity care. Even if women are at risk of dying on the way.... Because sometimes there is a flood, or something happens, they are in labour on the road, and sometimes it is a really difficult situation.

AXEL KROEGER: The peak of the interest for traditional birth attendance happened in the context of the primary health care movement in the 1970s, 80s, 90s. You had in Brazil very important training programs for traditional birth attendants, everybody talked about it. I lived for a long time in the house of a traditional birth attendant and I have seen how good she was in accompanying a normal pregnancy and birth, or birth with no-major complications. From time to time, the doctor came also to her house, and he said: "Oh, she is much better than we are, in being present during the childbirth". But in the context of "modernization" this is not any more fashionable. Of course, we have to recognize birth complications which can often not be handled by Traditional Birth and need specialized care, and therefore the stress on birth in the hospital we see, by the way the same here in Germany that midwives have to struggle to be accepted. They have been working for years and decades, and now they are under threat. "Oh, first you have to be in hospital". Home birth is not illegal yet, but the pressure is coming, and even if you can always say: "Okay, the hospital is...10 minutes in an ambulance away", there are still people who try to hinder them, to do this kind of work.

ALINE REGITANO: Yes, actually this just takes us to my next question. How we can think of public policies that value and legitimize non-hegemonic knowledge (of midwives and shamans, for example), considering at the same time the multiplicity of meanings attributed to practices and expertise in different contexts; and the legitimate power and monopoly of care that is exercised by the medical staff?

AXEL KROEGER: I think the principle is that private medicine is a business, and in business, you fight with competitors. Competitors are other private practitioners who belong to the same medical organization. It is easier to fight against informal medical 
practitioners in the non-formal health sector. This can be extremely strong, as our medical model is purely chemical-mechanistic or, let's say, based on science, nothing else is accepted. We have here in Germany, which I think is quite exceptional, Heilpraktiker, medical practitioners. These are health practitioners, who work mainly with non-informal services, such as homeopathy, ayurveda, acupuncture, etc. They are publicly accepted, but I see in my university, and I saw it already when I was at Heidelberg University, in the faculty meetings there was a lecturer on homeopathy who asked for an unpaid lectureship to explain to students about homeopathy and what it is all about. Many medical professors were totally against it: "No, no, this is not science, we can't show it to our students". At the same time, you find in the low and middle-income countries, medical doctors who are fighting for their income, and they do not want to have any kind of competition, and therefore this fight against the non-formal health services. One of the reasons, I would say.

FRANÇOISE BARBIRA-FREEDMAN: I thought about this question and...Yes, what Axel says about private medicine is right, but there are many NGOS, and I remember we used to talk a lot about-competition for charity. There were NGOs all over the place, particularly in the Amazon. They are still there, and they have, perhaps, less clout than they had when we were doing our work together, but they still have some potential and I see their potential as opening dialogues with indigenous people in the way that we have done in the past in medical anthropology, like... Margaret Lock, Patricia Kaufert, maybe also Kleinman, with his illness narratives, just trying to understand how local people understand their diseases, understand their categories of illness that we do not accept in the medical model, trying to understand how they perceive risk in their environment. I think there is a lot of scope for dialogue, and dialogue is always positive. The doctors start understanding that, maybe, their position is a bit irrational too, and then the other people are given a voice and start questioning about what is a disease as well. This is more the way I would answer your question, as an anthropologist, of course.

AXEL KROEGER: I think the compulsory program for recently graduated doctors to serve for six to twelve months in rural areas (called año rural) is an eye-opener. This is an opportunity for the young doctors to offer services and also to learn from the communities. I know quite a number of rural doctors who were really receptive and open, and always referred: "Oh in my año rural I have learned this or that", and they tell you extraordinary stories, what they have learned. Of course, it's not a very systematic way of understanding, but it's a dialogue and I'm quite sure that these people, yes, have served the communities although there's always a discussion: Is this second-class medicine what we are offering to the poorer socioeconomic groups? But I think this is a really good chance for the young doctors and I'm really impressed we have among our master students from Latin America. A young doctor from Mexico always talked about his experience during this time, when he 
was not in a big hospital, but in a small village and exposed to all these problems we are discussing.

FRANÇOISE BARBIRA-FREEDMAN: I completely agree and I have had students, even recently, who started anthropology from their year as a young doctor in a remote community, or in an urban suburb, with indigenous people. And I think that, maybe, there are more opportunities for anthropologists to gather and report on the experiences of these young doctors. Then, they go back to their countries' capital cities to work in the medical system and they might chat about their practice year's experiences, but...there is no systematic recording, or analysis of their experiences, and their experiences would be valuable.

AXEL KROEGER: Perhaps, it is also okay to add the question, how many of the young doctors stay afterwards in rural areas. I have seen once, in a survey among rural doctors in small towns of Mexico about their motives to stay there: The main reason was: "Oh, I have, now, a family here, and connections, but I started as a rural doctor and now I'm here". To go back to our current situation, here in Germany, we have a big problem to get doctors into "remote" areas: If you need half an hour or one hour in by car to get to the next city, the doctors do not want to stay there. One of the reasons is probably the selection of students. You can study medicine only if you are really top of top, you get the highest marks, and this is the only possibility to study medicine and this means that these people are proud of themselves: "Oh I have done it, I have achieved my goal, but now after so much effort why should I go to a rural area?”.

ALINE REGITANO: We have a profusion of incredible works that call Others to dance, vegetables, minerals, other than humans. I could mention, as an example, the work of Joana Cabral on leishmaniasis among the Wajãpi. In addition, unified and homogenizing regulations and rules continue to exist, requiring updates and refinement. How to think about health and public policies considering the interspecific relations, and the plurality of worlds and conceptions?

FRANÇOISE BARBIRA-FREEDMAN: I remember having many late-night conversations with Axel, about the plurality of worlds and perceptions, and how to deal with it and, again, I think it is about dialogue. It's about translation. It's about understanding the logic of the people we work with, so I think it's being open to their explanations and not excluding, that things can be living entities, not just plants and animals, but also their little spirits, or little disease carriers out there. The way we understand germs in popular culture is, in some ways, as irrational as the spirit darts of Amazonian indigenous people, and we need to come to terms with the common ground. I like her work because it is so poetic, the way of the 
Wajãpi, and well, all Amazonian people see the universe as animated, because they work with an animist outlook.

AXEL KROEGER: Perhaps I have an experience with cutaneous leishmaniasis, but mainly in Central America and on the Colombian Pacific coast. According to the people living in that area, a worm caused leishmaniasis. This worm is waiting in the leaves of the trees. If you get close to the leaves then the worm will attack you, and bite you, and produce the lesions of leishmaniasis, but if you see the worm before he attacks, then, you say "ya te vi" and then, the worm will not bite. Therefore, the disease is called yatevi (I have seen you). However, when they are too slow and get yatevi then they do treatment with plant medicines, or sometimes they use even battery acid or burn the lesion with cigarette, aggressive treatments. Therefore the importance of preventive measures namely to shout "ya te vi".

FRANÇOISE BARBIRA-FREEDMAN: Yeah, yeah, there is also a lot of interesting work about Malaria, not just in South America, but also in Africa, and there is a revival of some traditional remedies in some African countries. I think that we need to use these models when we have areas where there is already a positive dialogue and a positive understanding of different therapies, different strategies, which can be complementary. Then we need to use those as an example and reflect on this and build on this for other pathologies. Maybe, we need to fight the compartmentalization of our thinking about medical pluralism and healthcare in traditional areas, because there are bridges, but we need to find them, here and there, they are there.

AXEL KROEGER: Yes, I fully agree, and therefore I am happy also about our interview to see that the young generation continues to be interested in these areas, because it will be also important for the future, not only retrospectively, for the past, but you can use it.

ALINE REGITANO: Françoise, after long fieldwork periods in Peru, you return to Cambridge and as a mother and anthropologist, found a really beautiful and important movement, Birthlight. Axel, you have been dedicated to health studies for a long time, and now you work at WHO, focusing on tropical diseases. I would like you to tell us a little about your trajectories, and how you find it interesting to modulate theory and practice.

FRANÇOISE BARBIRA-FREEDMAN: I was thinking about this question. I gained two kinds of knowledge from my field work and one was anthropological knowledge, and you know, I still explore the particular question of what indigenous knowledge, how it is transmitted and how it is constituted. The other kind of knowledge I got was to the art of being in the sense Tim Ingold writes about this: I was learning to be in a different way, and I did not realize that this is what I was learning at the time. It took me a long time and I 
think it is through having several children that I really understood what I had learned from the women and from the midwives. I became an apprentice to a shaman-midwife after I finished working with Axel, in the 80s, and then I developed the same work in parallel, in Europe. Then, going back and forth, and back and forth, and just refining, finding some ways to translate these practices, for so that they would be available to western women, in a western environment lifestyle, and it became a fascination to do this. So, I sort of have parallel lives, but, I would say, it's about practical translation of knowledge that is not systematized, but it is systematic, it is consistent, it is orally transmitted through generations and I'm still exploring this. And, in the end I didn't write many anthropological books, but this is the book I want to write about, this kind of more subtle knowledge. That takes me back to Joanna Cabral, because I find her work really interesting, about how to understand the environment and how to perceive it, and the rhythms of being in gardens and of accompanying the tracks to find salt or to fish. It is a sort of embedded anthropology and I did not realize at the time how important it was, I was just getting data, but actually I got something else I had not bargained for, and I was not prepared for. The women here love it and all over the world it translates very easily, so that has also taken me by surprise, because I never intended to create a worldwide movement, that was not my intention.

AXEL KROEGER: So, I would say I benefited in all my professional life from this four-years experience in Ecuador. First, when I came back I started in a general hospital in Hamburg, which was difficult to re-adapt, but after re-adapting I was the only one asking for the cost of treatment and I had a very close relationship with patients, particularly those coming from other countries, other regions. You understand the feelings of a migrant, a person who feels alone, in the urban environment. After that, I did my master's in international community health, in London. I had classmates who had done three months of work for Save the Children Fund and now they knew the world. Therefore, I was much closer to students coming from Africa, or from Asia, Latin America, those with real field experiences. And this I've seen later working at universities, working in WHO, we have too many people working exclusively from their desk, without real field experiences. In public health, particularly in low and middle-income countries it's extremely important, for many health programs, to get communities involved; you see lots of theories how ministries want to change people's health behaviour, but it's often totally unrealistic. It cannot work without being aware of the way people are living and struggling for survival. So, for me, this time in the jungle was, until now, extremely important to always think back, be grateful for this experience and to apply many things which I have learned there.

ALINE REGITANO: What do you think of the notion of ontology as Annemarie Mol has been mobilizing, to think and experience our practices? 
FRANÇOISE BARBIRA-FREEDMAN: I know Annemarie Mol personally, and I am a fan of her, so I like her work very much and, yeah, she uses the word ontology, but actually she puts it into practice and that's what I like about her. She writes about care and, Axel, she is an anthropologist who is written two important studies, one about the treatment of atherosclerosis in a Dutch hospital and her other book is about the logic of care, and it is about the treatment of diabetes and how complex diabetes is as a disease label. She says that, in the logic of care she attacks the idea of patient choice, that patients are consumers, and they are treated as clients. She says that good care is not a matter of making well-argued individual choices, but something that grows out of collaborative and continuing attempts to attune knowledge and technologies to diseased bodies and complex lives. So, it's like a hit-and-miss attunement, that gets gradually better, but it's a process. It is not something that is fixed, and that is what I like about her idea of ontology, that it's not a given, it's something that evolves in the interaction between doctor and patient. When Axel was talking about his experience in the Hamburg hospital with migrant patients, I think there is a lot of that in her books as well, sort of how it is constituted in the lab, in the hospital, at home, so it's like much more complex than just doctor and patient, it includes all these environments.

AXEL KROEGER: I think diabetes is a good example for "blaming the victim" in clinical settings. Diabetes 2 has much to do with being overweight and lack of physical activity. So the doctors will say: "Oh, you didn't really practice physical activities, and you eat too much etc", so the patient himself is guilty of contracting the disease. This sense of guilt occurs also in other diseases where we tend to say: "Oh, it's psychosomatic", and the psycho is your part, you have done something wrong, you can't control yourself, you are the cause of your own disease. Some time ago, we did a nice study about health behaviour among Turkish migrant workers in Germany and German workers. We found in the hospital, but also in home settings, that for "psychosomatic" diseases the Turkish migrants of the first and second generation had a special disease label, I do not remember the name, indicating that ghosts are attacking the patient. This interpretation was good for everybody. The patient himself now does not think: "Oh, it's my fault, because there are powers coming from outside attacking me", and for the parents, or the husbands, to say: "Oh it's not her fault to be sick, it's coming from outside and we have to combat it". So, who is responsible for the disease is an important issue, particularly in chronic diseases.

ALINE REGITANO: How do you see the coronavirus global health crisis and its main implications? Does it aggravate pre-existing disease situations in the contexts you are familiar with? Does it bring structural changes, does it produce new problems?

AXEL KROEGER: We did a study on the dynamics of the pandemic in nine different countries, in two rich countries and in seven low and middle-income countries, using as 
information source mainly media, newspaper, articles, TV, etc. We also have direct contacts in all these countries with ex-students, or other people. What came frequently through the media was: that the pandemic is really explosive in separating social classes. And this is also very clear if you look at the informal economic sector: In India, you find $70 \%$ of all wage earners work in the informal sector and in Germany it is five percent. If the authorities lock down the whole population in a poor country you can expect that there will be a major impact on people's lives, including their health status. It is because they will die from hunger, instead of covid-19. This is a major challenge anywhere. Of course, the Brazilian example with an uncontrolled spread of Covid-19 is not very encouraging, but on the other hand, in countries with high unemployment rates and large informal sectors, we have to find alternative ways of dealing with the epidemic. What happened is that very early, India, Nepal, Bangladesh, Colombia, a bit less in Mexico, copied the European model of a complete lockdown with all the negative social and economic consequences. It went worse in Nigeria, which was one of the countries where there were fights and shootings on the streets when people tried to get food. So, the global health crisis has shown, or has brought to light, much more than in normal days, brought to light these social inequalities People were saying: "No, lock down is something for the middle and higher classes, but not for the poor people". This was also the case in indigenous areas. We have seen in many places that indigenous groups are particularly affected by infections and suffering particularly of severe diseases.

FRANÇOISE BARBIRA-FREEDMAN: So, I do not have such a wide-ranging experience, but I have been doing small-localised inquiries keyhole spot checks. One is in Colombian Amazonia where I have a former student, a colleague, living and working with indigenous people there. I have been following the situation in Peruvian Amazonia as well, and what seems to be happening is that there has been a revival of past strategies of dealing with epidemics. I do remember an epidemic of measles when I was doing my first fieldwork. At that time people are commenting also in Brazil, remembering what they did to fight the epidemic, and relying on the same strategies of withdrawing to more remote areas, being more self-sufficient and finding that actually they do very well by themselves. They do not needed to go to town every five minutes, and that they were relying on their three bark remedies. However, they only did this after a disastrous flurry of death of the old people including many shamans who died. Now they are creating new remedies based on the experience, they are exchanging recipes across tribal groups, so I think that is positive and interesting, and maybe the relations between indigenous groups and the states might change as a result. They will realize that they actually have more power than they do think, that they have enough land to go back.

AXEL KROEGER: And also, I have seen in Colombia that certain indigenous groups lock themselves up; they do not let outside people coming in which I think is a very reasonable strategy. 
ALINE REGITANO: Just to think more about what you said earlier, Françoise, about something missing. Do you have any clue for why it is not working even when there is a lot of goodwill?

FRANÇOISE BARBIRA-FREEDMAN: Well, Axel is the one who thinks about these things all the time [laughing].

AXEL KROEGER: No, it is difficult to understand. We wanted to do a study about bonesetters, because there you have a clear picture. You can do an $\mathrm{X}$-ray to see what is really wrong, and then to see if people are happier to go to the surgery, to the modern doctor, or if they prefer to go to the bone setter and where the treatment is more successful. However, it was very clear from the beginning that people make their choices and you cannot allocate them randomly to one or the other treatment, which would be a precondition for a clinical trial. So, the same happens, I suppose, with women going to a birth house, or going alternatively to the local traditional birth attendant, or going to the doctor. Some of those who prefer to go to the doctor, they go there, and they are not looking for traditional birth attendants. Those who stay and say: "I'm looking more for a traditional birth attendant", they would not go to the doctor, and so you have already from the beginning, a certain selfselection of what you prefer. If you offer, now, in the doctor's surgery, or in a small hospital, a traditional birth attendance scenery, people wouldn't go there, because they say: "Oh no, then I go directly to my traditional healer around the corner" or "I want to see the midwife or the doctor and therefore I go to the hospital".

FRANÇOISE BARBIRA-FREEDMAN: Yeah, I think I'll go back to the idea of dialogue and comparison. I agree about what Axel has just said. However, I remember of little diagrams of healer shopping and people would jump from going to the hospital and going to shaman, and then going back to the hospital, and people using all the services they could at the same time, more or less. I think they still do that. In my recent experience, they still do that, they go and get a massage from the midwife, but then, they go to the doctor in the hospital for their gestational check and I think they will always use everything.

AXEL KROEGER: This is, by the way, as a footnote. We are working with WHO in India, Bangladesh and Nepal on the elimination of visceral leishmaniasis, also a deadly, tropical disease, occurring mainly in poor remote areas. We were interested in how long it takes the patient to come to the diagnostic and treatment centre after the first signs of the disease have appeared. This was on average around four months to six months: Before they go there they do all what Françoise was describing, they go from one healer to the other. They first use all the local resources and possibilities and finally they get to the doctor. In Nepal, additionally, you have these large distances, you have to walk for six hours to get to the next health 
centre, but also in Bangladesh, where health services are more accessible people first try out what they find in their familiar environment, and finally, they get the diagnosis and treatment at the hospital.

FRANÇOISE BARBIRA-FREEDMAN: There are some interesting. Small cases that I can think of with my limited experience. I did a study on a plant that works as a local anaesthetic for the mucosa tissues, and we did a pilot with a dentist in Iquitos, in Peru. This dentist has a pro bono clinic, where he treats poor families particularly children who cannot afford a private dentist treatment. And he started using this plant to extract teeth and it worked and to this day people say: “Oh, I like it much better, because I don't like injections”. There are compromise solutions. The birth houses I think are really difficult options, because they haven't worked anywhere in the world, and we need to try and understand why, not insisting on banging heads to impose this sort of model, when all the evidence is that it doesn't work. But there are some-examples where people are very happy to use traditional remedies from the area that have been confirmed by science, or by research, and we need to replicate these instances, we need to build a portfolio of these examples, and say: "Yes, well, this works, this comes from your knowledge, and it's positive”. That said, the diagnosis is important, as well in the case of leishmaniasis, as Axel said, but I go back to malaria because I think it is a really interesting disease, and people will mix treatments, because they are not very good with consistency and it's very expensive, since the malaria drugs are very expensive.

ALINE REGITANO: What do you consider the main dilemmas and challenges posed to think and act in the health field today?

AXEL KROEGER: Perhaps, a general observation would be that the gap between poorer countries and richer countries is widening all the time, and this has to do with the more sophisticated machines medicine is using. For instance, we wanted to help colleagues from Afghanistan to learn simple laboratory techniques in a hospital, as they had opened, with German aid, a new hospital there. However, it was impossible to find a skilled person here as lab techniques are mainly automated, the lab technicians don't do what our parents' generation did. Finally, we found an old laboratory assistant, and she still knew the old procedures and was able to do the training. This situation you find in many places. You see in many poorer countries donations of machines from rich countries where nobody can use, or they may break down after half a year, and they are not any more of use. Another story is with the non-licensed drugs and intellectual property rights. The pharmaceutical industry is always fighting for licensed drugs and trying to avoid cheaper generic drugs. This was the painful experience with HIV/AIDS drugs until international agreements were signed to make them affordable for low-income countries. The same happened with other antiviral drugs (against avian flu or SARS) and it is currently happening with covid-19 vaccine. The 
richer countries will obtain the vaccine while the poorer countries have to wait. I think that industry is too dominant and the public services are too weak to make important drugs, diagnostics or vaccines available to the poor. There are many other examples showing how powerful the industry is to get things done, which may not always be the best ones to do.

FRANÇOISE BARBIRA-FREEDMAN: All right, oh, thank you, Axel, it is so refreshing to hear your thinking has not changed, and it's like, yeah, time has passed, but we think the same way still now, and it's great. Well, then... When I looked at Aline's question, I thought it is the way people use disposable drugs particularly for mental conditions,--throughout Latin America and it is reaching the indigenous people, so they take many of weird antidepressants, and they take far too many antibiotics. Like in childbirth, they will use several cartridges of oxytocin, everything is used in excess, because it's there, available to buy in many drug stores there. There is no real control at the grassroots, about the use of drugs pushed on people. My second dilemma would be that indeed, there is a gap between rich and poor, but there is also a greater gap between hospitals and communities. The people who used to be there, to link the two, are not there anymore. People themselves are the link, and they are a very vulnerable kind of link.

\section{References}

INGOLD, Tim. (2011). Being alive: essays on movement, knowledge and description. London: Routledge.

KAUFERT, Patricia. O'NEIL, John D. (1993). Analysis of a dialogue on risks in childbirth: clinicians, epidemiologists, and Inuit women. In: LINDENBAUM, Shirley; LOCK, Margaret (eds). Knowledge, power, and practice: the anthropology of medicine and everyday life. Berkeley: University of California Press.

KLEINMAN, Arthur. (1988). The illness narratives: Suffering, Healing and the Human Condition. New York: Basic Books.

LOCKE, Margaret; KAUFERT, Patricia. (1998). Pragmatic Women and Body Politics. Cambridge: Cambridge University Press.

MOL, Annemarie. (2008). The logic of care: Health and the Problem of Patient Choice. London: Routledge.

OLIVEIRA, Joana Cabral de. (2020). "As vicissitudes do matar. Conflitos ontológicos em um estudo sobre leishmaniose tegumentar americana na TI Wajãpi”, Horizontes Antropológicos vol. 57.

Recebido em 22/12/2020 
REGITANO | Interview with Axel Kroeger and Françoise Barbira-Freedman | 15

Aceito para publicação em 28/12/2020 